\title{
PRODUTO INOVADOR: REVISTA EDUCATIVA SOBRE ENGENHARIA DO TRABALHO
}

\author{
Arbene de Oliveira Aragão 1 \\ Gustavo Jose de Miranda Dantas ${ }^{2}$ \\ Suzany Dantas de Oliveira ${ }^{3}$ \\ Maria Aridenise Macena Fontenelle ${ }^{4}$
}

\begin{abstract}
RESUMO: O mercado de trabalho na área de Engenharia de Produção tem se expandido consideravelmente nos últimos tempos. Isso tem demandado para o profissional da área um volume cada vez maior de conhecimento que seja apresentado de forma acessível e de fácil compreensão. Por conta disso, o desenvolvimento de novos produtos com conceitos diferentes dos materiais de estudo comuns é necessário. Portanto, o artigo objetiva apresentar como se desenvolveu o projeto de um produto na área de Engenharia de Produção especificamente na disciplina de Projeto e Desenvolvimento de Produtos (PDP). A proposta lançada pela disciplina foi à criação de um jogo educativo, que promovesse a aprendizagem através de uma abordagem lúdica e divertida. Desta forma, foi escolhido o produto "Revista de Passatempos" utilizando conceitos técnicos do curso de Engenharia de Produção com temas da Engenharia do Trabalho.
\end{abstract}

Palavras-chave: PDP. Revista lúdica-educativa. Engenharia do Trabalho.

ABSTRACT: The labor market in the area of Production Engineering has expanded considerably in recent times. It has asked a professional working is a growing body of knowledge that is presented in an accessible and easy to understand way. Because of this, the development of new products with different concepts of common materials study is necessary. Therefore, the document aims to present how they developed the design of a product in the

\footnotetext{
1 Engenheira de produção, UFERSA, Universidade Federal Rural do Semi-Árido. E-mail bnearagao@yahoo.com.br

2 Engenheiro de produção, UFERSA, Universidade Federal Rural do Semi-Árido. E-mail gustavo_dantas@yahoo.com.br

3 Engenheiro de produção, UFERSA, Universidade Federal Rural do Semi-Árido. E-mail suzanydantas@hotmail.com

4 Docente do Departamento de Ciências Ambientais e Tecnológicas da UFERSA, Universidade Federal Rural do Semi-Árido. E-mail aridenise@ufersa.edu.br
}

ReLAInEP - Revista Latino-America de Inovação e Engenharia de Produção, Curitiba, PR, Brasil, v. 3, n. 4, p. 24-49, 2015. 


\section{ReLAInEP}

area of Production Engineering specifically in the discipline of Design and Product Development (PDP). The proposal made by the discipline was to create an educational game that promotes learning through playful and fun approach. Thus, the product "Hobbies Magazine" using technical concepts of Production Engineering golf-themed Engineering Labor was elected.

\section{Key words: PDP. Playful-educational magazine. Engineering work}

RESUMEN: El mercado de trabajo en el área de Ingeniería de Producción se ha ampliado considerablemente en los últimos tiempos. Se ha pedido a los profesionales que trabajan un creciente cuerpo de conocimiento que se presenta de una manera accesible y fácil de entender. Debido a esto, el desarrollo de nuevos productos con diferentes conceptos de materiales de estudio comunes es necesario. Por lo tanto, el documento tiene como objetivo presentar cómo se desarrolló el diseño de un producto en el área de Ingeniería de Producción específicamente en la disciplina de Diseño y Desarrollo de Productos (PDP). La propuesta lanzada por la disciplina era crear un juego educativo que promueve el aprendizaje a través del enfoque lúdico y divertido. De esta manera, el producto "Pasatiempos Revista" utilizando conceptos técnicos de Ingeniería de Producción de golf con temas de Ingeniería del Trabajo fue elegido.

Palabras-clave: PDP. Revista Juguetón-educativo. Trabajo de Ingeniería.

\section{INTRODUÇÃO}

O mercado de trabalho na área de Engenharia de Produção tem se expandido consideravelmente nos últimos tempos. Isso tem demandado para o profissional da área um volume cada vez maior de conhecimento que seja apresentado de forma acessível e de fácil compreensão.

Por conta disso, o desenvolvimento de novos produtos com conceitos diferentes dos materiais de estudo comuns é necessário. Existem várias vertentes no estudo de Projeto e Desenvolvimento de Produtos, mas todas elas consideram que a elaboração do "Conceito" do produto ou processo é o ponto crucial de partida para o sucesso do projeto; visto que o cliente não compra só um produto, mas sim o conceito, ou seja, o que aquele produto pode dizer sobre sua personalidade, hábitos e desejos.

Diversos autores comentam que um bom projeto deve reunir três etapas básicas, com pequenas variações: pré-desenvolvimento - que envolve o planejamento estratégico da

ReLAInEP - Revista Latino-America de Inovação e Engenharia de Produção, Curitiba, PR, Brasil, v. 3, n. 4, p. 25 - 50, 2015. 


\section{ReLAInEP}

implantação de um ou uma série de novos produtos/serviços para a organização, Desenvolvimento - nesta fase é escolhido o produto com maior potencial e criada toda a estrutura conceitual, informacional, detalhamento e preparação para a produção e Pósdesenvolvimento - que consiste na produção e comercialização propriamente dita, etapa que geralmente é realizada por outro grupo da organização que não o de projeto.

A disciplina de Projeto e Desenvolvimento de Produtos aborda as duas primeiras fases citadas, com enfoque principal na fase do Desenvolvimento do Projeto, encerrando com a prototipagem do produto criado. A proposta lançada pela disciplina foi à criação de um jogo educativo, que promovesse a aprendizagem através de uma abordagem lúdica e divertida. Desta forma, foi escolhido o produto "Revista de Passatempos" utilizando conceitos técnicos do curso de Engenharia de Produção.

\section{METODOLOGIA}

O presente projeto de produto se iniciou com o estudo de alguns modelos científicos para a atividade de projetos apresentados na literatura, identificando suas principais etapas. Após o conhecimento dos principais modelos, optou-se pelo modelo mais adequado ao projeto pretendido, seguindo as etapas sugeridas pelo mesmo; desenvolveu-se o projeto gradativamente na medida em que as etapas eram concluídas.

Após a definição do escopo do projeto e produto, foi realizada uma previsão de demanda simplificada, esclarecendo quais as expectativas do cliente para o produto e sua aceitação em termos de conteúdo, design e preço. No seguimento foram definidas as especificações básicas para o produto, de acordo com os desejos esboçados pelo cliente na pesquisa de mercado, culminando na concepção do produto propriamente dito (conteúdo técnico, projeto gráfico etc.). Após definidas suas especificações finais, foram definidas estratégias de produção simplificadas para o produto e o desenvolvimento do protótipo do produto final. Para finalizar o projeto aplicou-se o protótipo para avaliação do consumidor, bem como foram definidos os recursos necessários e o plano de fim de vida do produto.

O presente roteiro deste artigo descreverá como se deu a execução das etapas para o desenvolvimento do primeiro exemplar da Revista Lúdico-Educativa.

ReLAInEP - Revista Latino-America de Inovação e Engenharia de Produção, Curitiba, PR, Brasil, v. 3, n. 4, p. 25 - 50, 2015. 


\section{ReLAInEP}

\section{REVISÃO BIBLIOGRÁFICA}

\subsection{Fase 1 - Pré-desenvolvimento - Planejamento estratégico}

Rozenfeld et al. (2006) define que na fase de Pré-Desenvolvimento de um projeto "são consideradas as estratégias de mercado da empresa e também as tecnológicas, (...) para cada mercado define-se um conjunto de produtos, conhecido por portfólio (...), mas finalmente, apenas alguns produtos serão lançados, todos eles viáveis e com grande probabilidade de sucesso no mercado".

Slack et al (2002) desconsidera esta fase inicial, os autores citam que "o projeto de produtos e serviços tem início no consumidor e nele termina." Percebe-se que o projeto de novos produtos não atenderia um planejamento estratégico da empresa, mas sim atenderia a uma demanda sinalizada pelo consumidor, identificada pelo marketing da empresa e operacionalizada pelo setor de projetos, criando as especificações para o produto ou serviço.

Keeling (2002) ao contrário, prevê a fase de planejamento estratégico da empresa como um conjunto de projetos viáveis, executados simultaneamente dentro da organização: "A administração de projetos múltiplos vincula um conjunto de projetos: estrategicamente, por meio do planejamento de portfólio; tecnologicamente, devido a componentes comuns; ou mediante a sobreposição da administração de projetos, por exemplo, na forma de um programa".

O presente projeto deste artigo não está incluído no planejamento estratégico de uma organização, mas obedece a uma proposta/motivação oferecida pela disciplina de Projeto e Desenvolvimento de Produtos. Desta forma, o aprofundamento foi dado na fase de Desenvolvimento, seguindo o modelo de Desenvolvimento de Produto proposto por Rozenfeld et al. (2006) considerado o mais adequado para o produto desenvolvido.

\subsection{Fase 2 - Desenvolvimento de produto}

O modelo de Desenvolvimento de Produto proposto por Rozenfeld et al. (2006) "enfatiza os aspectos tecnológicos correspondentes à definição do produto em si, suas características e

ReLAInEP - Revista Latino-America de Inovação e Engenharia de Produção, Curitiba, PR, Brasil, v. 3, n. 4, p. 25 - 50, 2015. 


\section{ReLAInEP}

forma de produção; tais atividades são dependentes da tecnologia envolvida no produto." A figura a seguir apresenta a visão geral do modelo proposto pelos autores.

Figura 1: Processo de Desenvolvimento de Produto

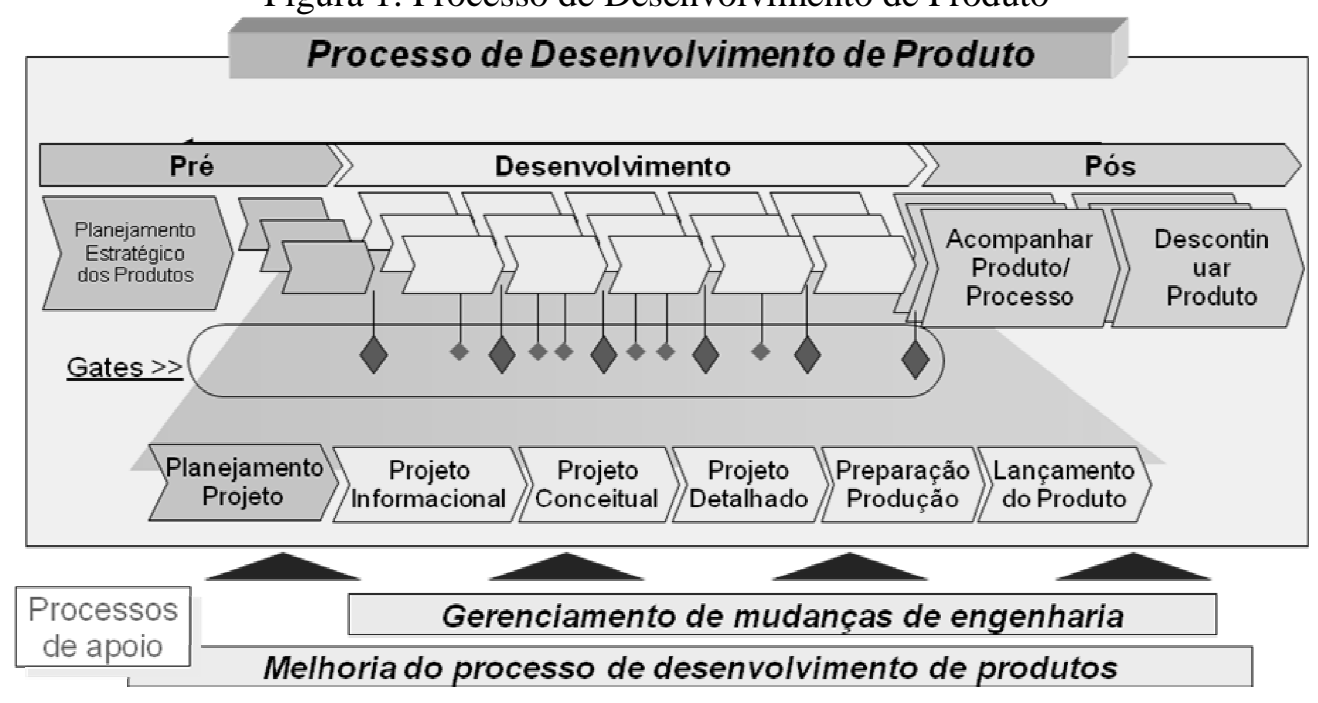

Fonte: Rozenfeld et al. (2006)

Os autores iniciaram a fase de Desenvolvimento pelo estudo do documento gerado na fase anterior, o "Plano do Projeto", no qual foi definido o escopo do projeto e do produto, quais as atividades, pessoal, prazos, riscos etc., envolvidos no projeto do produto.

No Desenvolvimento propriamente dito, ocorreu a elaboração do Projeto Informacional que criou as "Especificações-meta" do futuro produto, contendo as informações qualitativas do mesmo.

No seguimento foi elaborado o Plano Conceitual, no qual as especificações-metas foram detalhadas, de forma a obter uma definição mais apurada do produto, gerando o documento “Concepção do Produto".

Na fase seguinte, no Projeto Detalhado, foram desenvolvidas as "Especificações Finais" para o produto, que conterá os documentos "Protótipo Funcional", "Projeto de Recursos" e "Plano de Fim de Vida" do produto.

A etapa seguinte do Desenvolvimento é a Preparação da Produção que envolve a certificação do produto, após os testes piloto, realizados na linha de produção. Uma vez aprovado, a empresa poderá produzi-lo em série e efetuar o "Lançamento do Produto" para o mercado, prevendo e documentando suas vendas, distribuição, marketing, assistência técnica, atendimento ao cliente, etc. Após a fase de Desenvolvimento, os autores apresentam o Pós-

ReLAInEP - Revista Latino-America de Inovação e Engenharia de Produção, Curitiba, PR, Brasil, v. 3, n. 4, p. 25 - 50, 2015. 


\section{ReLAInEP}

Desenvolvimento, que consiste no acompanhamento do produto durante seu ciclo de vida: iniciação, maturação, declínio e fim de vida do produto.

\subsection{Fase 3 - Pós-Desenvolvimento}

Rozenfeld et al (2006) é o autor que mais contempla essa fase, a qual se inicia após o lançamento do produto, com sua produção e comercialização. $O$ autor comenta que normalmente a equipe de projeto é desfeita e seus membros alocados em outros projetos. Porém, o processo de desenvolvimento de produtos continua através do acompanhamento de seu ciclo de vida; além de manter um aprimoramento constante e correção de eventuais defeitos, com uma boa assistência técnica e serviço de atendimento ao cliente.

A fase de Pós-desenvolvimento não foi apresentada no presente projeto, pois não se tratava de um lançamento de produto em larga escala, mas foi finalizado com a avaliação do cliente no momento da apresentação do produto.

\section{METODOLOGIA DE APLICAÇÃO DO MODELO DE ROZENFELD}

O presente projeto foi baseado no Modelo de Rozenfeld et al (2006) tomando como referência suas etapas básicas e seus respectivos documentos. Entretanto, como o projeto do produto escolhido REVISTA DE PASSATEMPOS LÚDICO-EDUCATIVA é relativamente simples, algumas partes dos documentos foram excluídas ou modificadas, de forma a criar um projeto personalizado.

O primeiro passo, numa simplificação da etapa de Pré-desenvolvimento, foi a elaboração do Plano de Projeto (Documento 1) a partir da proposta inicial da disciplina, no qual foram definidos os escopos do projeto e do produto; delimitando as características iniciais do projeto como atividades, pessoal, prazos, orçamento, recursos, qualidade e riscos.

ReLAInEP - Revista Latino-America de Inovação e Engenharia de Produção, Curitiba, PR, Brasil, v. 3, n. 4, p. 25 - 50, 2015. 


\section{ReLAInEP}

Em seguida, foi iniciada a fase de Desenvolvimento, com a elaboração de um diagrama explicativo de todas as fases do projeto, baseado no modelo adotado. Cada fase executada gerou o seu respectivo documento, que montarão o projeto final do produto.

A primeira etapa foi o Projeto Informacional, que gerou o documento EspecificaçõesMeta (Documento 2), o qual foi iniciado a partir da identificação da demanda para o produto escolhido e do conhecimento do cliente potencial

A pesquisa de mercado consistiu na aplicação de um questionário contendo questões abertas e fechadas, seguido por entrevistas para verificar quais as necessidades/desejos do consumidor. No seguimento, foram analisados os resultados e definidas as especificações iniciais para o futuro produto.

A segunda etapa realizada foi o Projeto Conceitual, no qual foi definido o conceito do produto obtido a partir das especificações-meta da etapa anterior. Slack (2002) determina esta etapa de definição do Conceito como crucial para o sucesso de um novo produto.

A terceira etapa do projeto foi a elaboração do Projeto Detalhado, no qual constaram as características físicas e funcionais do produto, bem como sua arquitetura, a lista de materiais necessários e as técnicas utilizadas para sua produção, resultando no documento Especificações Finais.

Após definidas as especificações passou-se à criação do protótipo final, que gerou um modelo virtual criados em softwares como Word, Excel e CorelDraw, resultando em arquivos utilizados para impressão do modelo real.

A análise dos recursos foi à etapa seguinte, considerando dois processos possíveis: a impressão terceirizada e a criação de uma empresa gráfica. Os custos apresentados basearamse nos custos reais do protótipo para a primeira opção e em dados obtidos no site do SEBRAE destinados a empreendedores interessados no ramo gráfico.

Finalizando o projeto da REVISTA LÚDICO-EDUCATIVA apresentou-se o Plano de Fim de Vida do Produto, no qual foram sugeridas algumas ações para a destinação final da revista após o seu uso.

As etapas finais presentes na fase de Desenvolvimento proposta pelos autores foram a Preparação da Produção e o Lançamento do Produto destinado às empresas reais, sendo mais complexas e contendo um nível de detalhe que foge ao escopo deste trabalho.

ReLAInEP - Revista Latino-America de Inovação e Engenharia de Produção, Curitiba, PR, Brasil, v. 3, n. 4, p. 25 - 50, 2015. 


\section{RESULTADOS DA APLICAÇÃO DO MODELO DE ROZENFELD}

O modelo de Rozenfeld et al (2006) foi considerado o mais adequado ao projeto da REVISTA LÚDICO-EDUCATIVA, entretanto o modelo foi adaptado à realidade do projeto, sendo algumas etapas omitidas e outras modificadas por conta da simplicidade do produto.

No princípio do estudo elaborou-se uma representação gráfica das adaptações efetuadas, indicando quais etapas foram executadas dentro do modelo, mostrando o fluxo do processo criativo da revista apresentado na figura a seguir.

No seguimento foram apresentados os documentos gerados em cada fase do projeto, com uma breve definição de cada, apresentando a evolução dos conhecimentos ao longo do ciclo de vida do projeto (figura 2).

Figura 2: Representação gráfica do projeto da revista lúdico-educativa

ReLAInEP - Revista Latino-America de Inovação e Engenharia de Produção, Curitiba, PR, Brasil, v. 3, n. 4, p. 25 - 50, 2015. 


\section{ReLAInEP}

DESENVOLVIMENTO DE PRODUTO

PlanEJAMENTO

A - Planejamento do Projeto
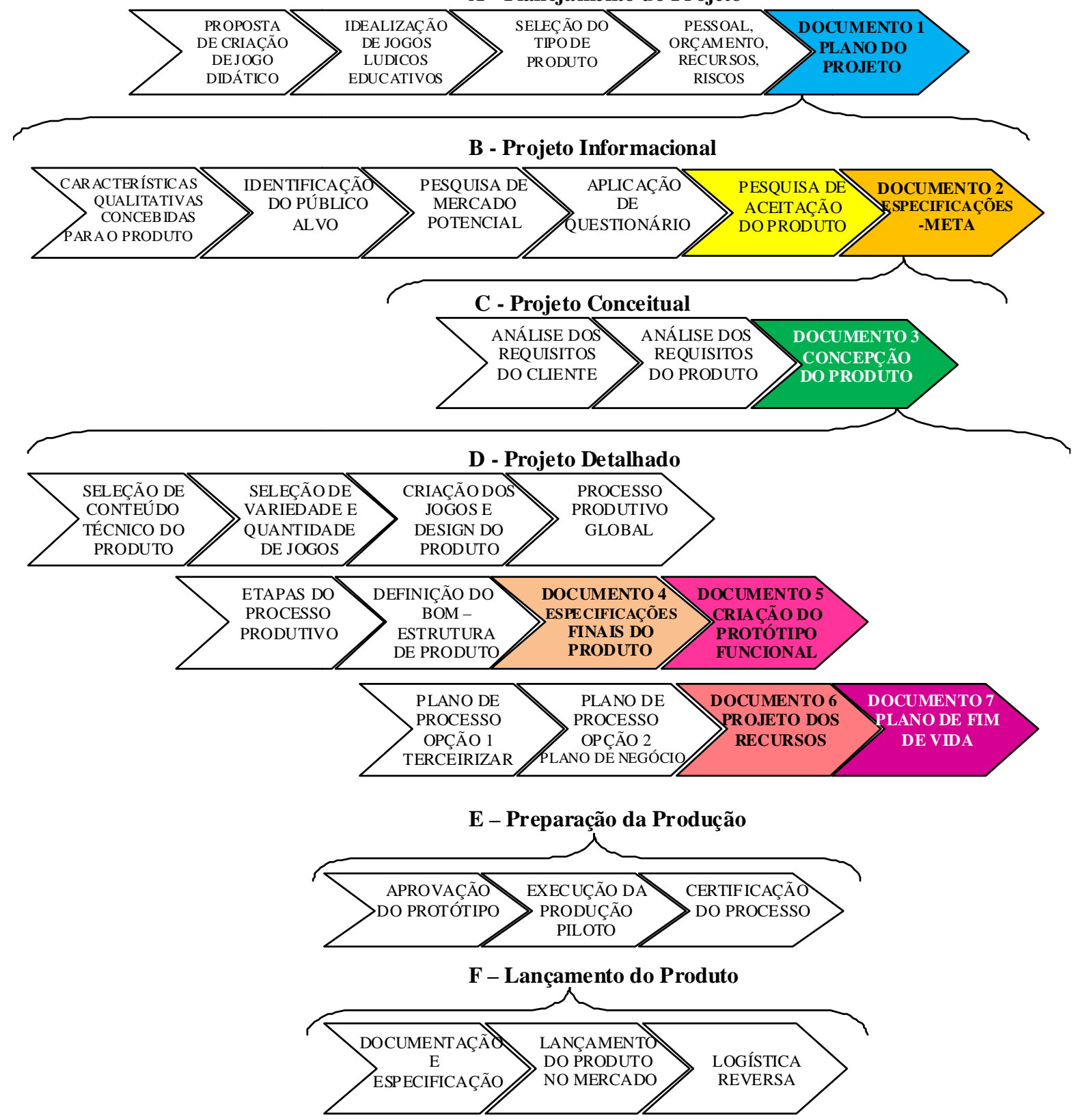

Fonte: Adaptado de Rozenfeld et al. (2006)

\section{DOCUMENTO 1 - PLANO DO PROJETO}

ReLAInEP - Revista Latino-America de Inovação e Engenharia de Produção, Curitiba, PR, Brasil, v. 3, n. 4, p. 25 - 50, 2015. 


\section{ReLAInEP}

Consiste na descrição das ações e recursos a serem empregados pela empresa, visando à obtenção de um novo produto. É resultado do Planejamento do Projeto (Rozenfeld et al, 2006).

\section{A - Escopo do projeto}

O projeto teve como motivação a avaliação final da disciplina de Projeto e Desenvolvimento de Produto, na qual foi lançada a proposta de elaboração de jogo educativo na área de Engenharia de Produção. O projeto foi elaborado na forma de um conceito útil e lúdico, apresentando todo o processo de criação, como também operacionalizado na forma de um protótipo do produto, testado com os clientes potenciais (colegas de turma). Os responsáveis por todas as etapas do projeto foram três alunos que estiveram sido avaliados conforme o sucesso do protótipo obtido.

\section{B - Escopo do produto}

Com o aumento da demanda por conhecimento técnico, verificou-se a necessidade de criar maneiras mais lúdicas de adquirir este conhecimento. Tanto para estudantes em formação como para profissionais graduados, portanto fez-se necessária a existência de um material que reunisse conceitos básicos e práticos para uso no cotidiano, mas que também tivesse uma apresentação divertida e com maior facilidade de memorização. Com isso, surgiu a ideia de se produzir uma Revista de Passatempos, contendo conceitos técnicos e uma apresentação lúdico-educativa para auxiliar o profissional e/ou estudante da área de Engenharia de Produção.

\section{C - Atividades, pessoal e prazos}

As atividades para o desenvolvimento do projeto foram realizadas segundo um planejamento prévio, incluindo as demandas de pessoal e os prazos respectivos, assim elencaram-se todas as tarefas desenvolvidas no projeto, a partir de:

- Pesquisa Bibliográfica;

- Idealização do produto - Reuniões de Brainstorming;

- Seleção do tipo de produto;

- Definição da divisão de tarefas, orçamento, recursos, riscos, etc.;

- Elaboração do Plano de Projeto;

ReLAInEP - Revista Latino-America de Inovação e Engenharia de Produção, Curitiba, PR, Brasil, v. 3, n. 4, p. 25 - 50, 2015. 


\section{ReLAInEP}

- Pesquisa de Mercado - Definição do público alvo; Elaboração do questionário; Aplicação do questionário; Análise dos Requisitos do cliente e do produto;

- Elaboração Especificações-Meta;

- Concepção do Produto;

- Seleção - Do Conteúdo Técnico do Produto; Da Variedade e Quantidade de Jogos;

- Criação dos jogos - Direta e Dominox; Caça-Palavras, Criptograma e Caça-Posturas; Sinaligação e jogo dos Sete erros;

- Definição - Da Arquitetura do produto; Das Especificações Finais do Produto; Do BOM Estrutura de Produto (matérias-primas);

- Criação do Protótipo Funcional;

- Projeto de Recursos;

- Plano de Processo - Opção 1: Terceirizar impressão; Opção 2: Plano de negócio- Criação de Empresa Gráfica;

- Plano de Fim de Vida;

- Avaliação do Protótipo pelo Cliente

- Apresentação dos resultados

- Finalização do Projeto

\section{D - Orçamento}

O orçamento do projeto foi concretizado após a definição das características finais do produto, visto que a sugestão inicial da disciplina encerrava o projeto na fase de elaboração do protótipo funcional e o projeto em si não envolveu custos adicionais, além do capital intelectual empregado.

\section{E - Recursos}

Os recursos físicos utilizados constituíram de computadores e softwares, bem como bibliografia técnica para a fase de desenvolvimento do projeto, e recursos audiovisuais na fase de apresentação dos resultados.

\section{F - Qualidade}

As metas de qualidade atribuídas ao projeto foram definidas pela Docente da disciplina e avaliadas continuamente pela mesma no desenrolar do projeto como parte integrante de uma das avaliações dos referidos docentes.

ReLAInEP - Revista Latino-America de Inovação e Engenharia de Produção, Curitiba, PR, Brasil, v. 3, n. 4, p. 25 - 50, 2015. 


\section{ReLAInEP}

\section{G - Riscos}

Os riscos do projeto foram basicamente as dificuldades para obtenção dos conceitos técnicos, o pouco conhecimento de softwares específicos para diagramação (Photoshop, Coreldraw, etc.) e o não atendimento aos prazos pré-determinados.

\section{DOCUMENTO 2 - ESPECIFICACÕES-META}

Conjunto de objetivos ou metas que o produto deve atender. Este conjunto de informações, elaborado durante o Projeto Informacional do produto, deve refletir as características que o produto deverá ter para atender às necessidades do cliente. (Rozenfeld et al, 2006).

\section{A - IDENTIFICAÇÃO DA DEMANDA}

\section{A.1 Expectativas iniciais para o mercado potencial}

As expectativas dos idealizadores do projeto para o mercado potencial do produto a ser desenvolvido é a sua utilização em diversos âmbitos:

a) Profissional - como forma de memorização dos conceitos teóricos de Engenharia de Produção, bem como de normas regulamentadoras e legislações aplicadas às empresas em geral;

b) Acadêmico - Alunos e professores poderão utilizar o material como auxiliar didático em aulas e provas;

c) Concursos - A facilidade de memorização dos conceitos pode ser um forte aliado na preparação para concursos públicos.

O processo de identificar uma demanda por um novo produto deve ser feito de forma rigorosa, através de pesquisas de mercado com o público alvo que se deseja atingir. A literatura indica que sejam feitos questionários abertos e fechados para sondar as expectativas do consumidor com relação ao produto que se deseja lançar. O questionário aplicado está presente no ANEXO I e a análise das respostas apresentou os seguintes resultados.

\section{A.2 Resultados da pesquisa de mercado}

ReLAInEP - Revista Latino-America de Inovação e Engenharia de Produção, Curitiba, PR, Brasil, v. 3, n. 4, p. 25 - 50, 2015. 
A população pesquisada consistiu de $47 \%$ de estudantes de Graduação, $10 \%$ de estudantes de Pós-graduação, 30\% de profissionais graduados na área de Engenharia de Produção e $13 \%$ de profissionais de outras áreas, mas com interesse pelo assunto.

Dos entrevistados observou-se uma aceitação de $97 \%$ para a proposta de um material didático, lúdico e divertido para estudo dos conceitos de Engenharia de Produção e 87\% acharam o conceito de Revisa de Passatempos interessante.

Os objetivos apontados pelos entrevistados para o uso do material de estudo seria o que está disposto na tabela a seguir:

Tabela 1: Objetivos apontados pelos entrevistados para o uso do material de estudo.

\begin{tabular}{|c|c|c|}
\hline Objetivos & Respostas & Percentagem \\
\hline Concursos & 14 & $47 \%$ \\
\hline Trabalho & 3 & $10 \%$ \\
\hline Faculdade & 9 & $30 \%$ \\
\hline Passatempo & 4 & $13 \%$ \\
\hline
\end{tabular}

Fonte: Elaborado pelo autor

Verifica-se que o objetivo "concursos" aparece como o preferido com 47\%, seguido de "faculdade" com 30\%, indicando uma demanda potencial mais presente no meio acadêmico do que no profissional. Confirmando a demanda, observou-se que $93 \%$ dos entrevistados comprariam o material como auxiliar na assimilação dos conteúdos.

Quanto ao valor que os entrevistados estariam dispostos a pagar pelo material observase que o valor até $\mathrm{R} \$ 15,00$ foi preferido por $63 \%$ e até $\mathrm{R} \$ 30,00$ foi apontado por 27\%; indicando que $90 \%$ da população amostrada não pagaria mais do que isso pelo material. Esta informação impacta diretamente no planejamento de custos para o projeto da revista, visto que para obter um retorno financeiro deve ser levada em conta a perspectiva de preço apontada pelo consumidor.

Nos quesitos Design x Conteúdo da revista, foi apontado pelo potencial consumidor pelo sistema de preferências heurístico uma nota de maior valor para CONTEÚDO TÉCNICO, sendo os outros quesitos apontados com notas bastante semelhantes, indicando que são indiferentes entre si. Estes dados permitem gerar um material de menor custo; visto que o cliente sinalizou que é possível reduzir a qualidade do matéria-prima, contanto que se mantenha um conteúdo adequado.

ReLAInEP - Revista Latino-America de Inovação e Engenharia de Produção, Curitiba, PR, Brasil, v. 3, n. 4, p. 25 - 50, 2015. 


\section{ReLAInEF}

ReLAInEP - Revista Latino-America de Inovação e Engenharia de Produção, Curitiba, PR, Brasil, v. 3, n. 4, p. 25 - 50, 2015. 


\section{ReLAInEP}

Tabela 2: Requisitos de maior importância para os entrevistados.

\begin{tabular}{|l|l|}
\hline Requisitos & Nota \\
\hline Visual da revista & 7,93 \\
\hline Qualidade do papel & 7,40 \\
\hline Qualidade da impressão & 7,93 \\
\hline Conteúdo técnico & 10,00 \\
\hline Variedade de jogos & 8,13 \\
\hline Quantidade de jogos & 7,80 \\
\hline
\end{tabular}

Fonte: Elaborado pelo autor

Os assuntos preferidos pelo consumidor obtiveram as seguintes porcentagens, onde a Aplicação Prática apareceu em primeiro lugar, seguida de Conceitos Teóricos.

Tabela 3: Assuntos preferidos para os entrevistados.

\begin{tabular}{|c|c|c|}
\hline ASSUNTOS PREFERIDOS & Respostas & Percentagem \\
\hline Conceitos Teóricos & 11 & $37 \%$ \\
\hline Legislação & 4 & $13 \%$ \\
\hline Aplicação Prática & 15 & $50 \%$ \\
\hline
\end{tabular}

Fonte: Elaborado pelo autor

Quando foram apresentados os assuntos específicos da área de Engenharia de Produção, representados pelas 10 áreas da ABEPRO, foi solicitado ao cliente que numerasse as áreas em ordem de importância (1 - Para mais importante a 10 - Para menos importante), observou-se o seguinte resultado:

Tabela 4: Preferência dos entrevistados pelas áreas da Engenharia de Produção

\begin{tabular}{|l|c|}
\hline Áreas da engenharia de produção & Média \\
\hline Engenharia de Operações e Proc. da Produção & 4,5 \\
\hline Logística & 6 \\
\hline Pesquisa Operacional & 6,5 \\
\hline Engenharia da Qualidade & 5 \\
\hline Engenharia do Produto & 5 \\
\hline Engenharia Organizacional & 6 \\
\hline Engenharia Econômica & 4 \\
\hline Engenharia do Trabalho & 8 \\
\hline Engenharia da Sustentabilidade & 10 \\
\hline Educação em Eng. De Produção & 3 \\
\hline
\end{tabular}

Fonte: Elaborado pelo autor

ReLAInEP - Revista Latino-America de Inovação e Engenharia de Produção, Curitiba, PR, Brasil, v. 3, n. 4, p. 25 - 50, 2015. 


\section{ReLAInEP}

A área de Engenharia do Trabalho recebeu a melhor avaliação com nota 3, seguido por Engenharia Econômica e Engenharia de Operações. Engenharia de Qualidade e Engenharia do Produto tiveram avaliação média.

Com relação aos tipos de jogos preferidos pelo consumidor, verifica-se na tabela a seguir que Caça-palavras, Palavra Cruzada, Jogo dos Erros e Criptograma obtiveram melhores notas, e os demais um patamar inferior, mas ainda próximo.

Tabela 5: Preferencia do Consumidor

\begin{tabular}{|c|c|}
\hline Tipos de jogos & Nota \\
\hline Criptograma & 7,40 \\
\hline Palavra Cruzada & 8,33 \\
\hline Caça-Palavra & 8,20 \\
\hline Dominox & 6,80 \\
\hline Direta & 5,80 \\
\hline Jogos dos erros & 8,07 \\
\hline
\end{tabular}

Fonte: Elaborado pelo autor

Os dados indicam que todos os jogos possuem uma parcela considerável de apreciadores, logo, o material deverá ser o mais diverso possível para agradar uma porção maior de clientes potenciais.

\section{B - Requisitos com valores-meta}

Os requisitos básicos indicados pela pesquisa de mercado para o produto Revista Lúdico-Educativa são os definidos a seguir:

B.1 Material DIDÁTICO, LÚDICO E DIVERTIDO para estudo contendo conceitos de Engenharia de Produção;

B.2 Material contendo conceitos para uso em estudos para CONCURSOS e FACULDADE;

B.3 Material bem aceito pelo cliente, com grande probabilidade de comercialização, com VALOR MÍNIMO DE R \$15,00 E MÁXIMO DE R \$ 30,00;

B.4 Material com CONTEÚDO TÉCNICO mais importante que qualidade do papel ou design gráfico;

B.5 Material contendo preferencialmente APLICAÇÃO PRÁTICA e CONCEITOS TEÓRICOS;

ReLAInEP - Revista Latino-America de Inovação e Engenharia de Produção, Curitiba, PR, Brasil, v. 3, n. 4, p. 25 - 50, 2015. 


\section{ReLAInEP}

B.6 A área da Engenharia de Produção preferida foi ENGENHARIA DO TRABALHO, por conta disso, optou-se por assuntos pertencentes à área, inicialmente SEGURANÇA DO TRABALHO E ERGONOMIA;

B.7 Os jogos preferidos foram Caça-palavras, Palavra Cruzada, Jogo dos Erros e Criptograma; logo deve haver DIVERSOS TIPOS DE JOGOS para agradar os clientes.

\section{DOCUMENTO 3 - CONCEPCÃO DO PRODUTO}

A geração do conceito iniciou-se da proposta inicial de criar um jogo didático na área de Engenharia de Produção, entretanto, o processo de identificação da demanda facilitou a visualização da estrutura básica do material como uma revista de passatempos, com conteúdo técnico, visando dar apoio às diversas atividades de estudo para estudantes e profissionais.

Assim, o conceito definido para o produto seria a criação de uma Revista de Jogos Passatempos; com base nos conteúdos técnicos de Segurança do Trabalho e de Ergonomia; visando utilização acadêmica e profissional; com custo reduzido; apresentando pelo menos um jogo de cada tipo, bem como novas propostas de jogos didáticos; visando a fixação de conceitos técnicos de forma lúdica, educativa e divertida.

\section{DOCUMENTO 4 - ESPECIFICACÕES FINAIS -}

\section{A - PROCESSO PRODUTIVO GLOBAL}

Como será elaborado apenas o protótipo e não será feita uma produção industrial em escala, os processos de produção serão bastante simplificados como expostos na lista e no fluxograma a seguir:

Etapa I - Processo de pesquisa dos conteúdos técnicos e ilustrações

Etapa II - Criação dos Jogos

Etapa III - Diagramação da Revista

Etapa IV - Impressão da Revista

Etapa V - Dobra, Montagem e Corte dos excessos das páginas

Etapa VI - Distribuição

ReLAInEP - Revista Latino-America de Inovação e Engenharia de Produção, Curitiba, PR, Brasil, v. 3, n. 4, p. 25 - 50, 2015. 


\section{ReLAInEP}

Figura 3 - Fluxos do processo - Informação e materiais

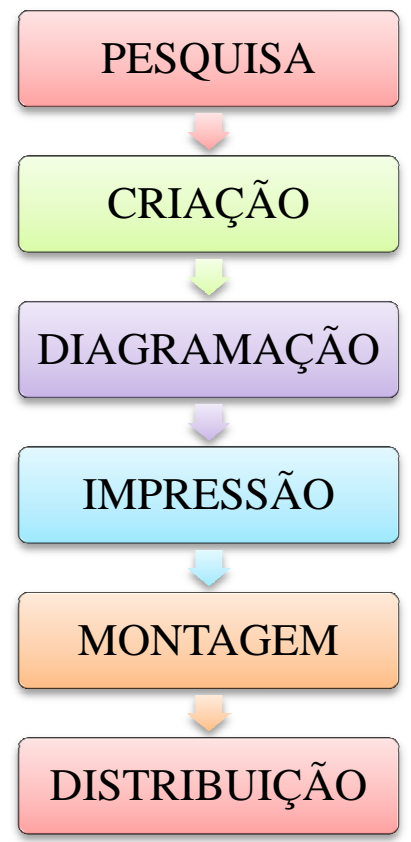

\section{B - ESPECIFICAÇÕES DAS ETAPAS DO PROCESSO}

\section{Etapa I - Processo de pesquisa dos conteúdos técnicos e ilustrações}

A construção dos jogos será baseada em conteúdos técnicos na área de Segurança do Trabalho e Ergonomia, consultada em livros especializados e em normas regulamentadoras da área encontradas no site do Ministério do Trabalho e Emprego. As figuras utilizadas serão pesquisadas na internet, em sites ligados aos assuntos abordados e devidamente referenciados ao final da revista.

\section{Etapa II - Criação dos Jogos}

Rozenfeld et al (2006) definem que a arquitetura do produto contempla como os elementos funcionais do produto são arranjados fisicamente e como interagem.

Desta forma, a REVISTA LÚDICO-EDUCATIVA projetada terá a arquitetura definida pelo número e tipo de jogos determinados, sendo elaborada contendo no mínimo 07 jogos diferentes, alguns inéditos e outros de tipos conhecidos como Direta, Caça-palavras, Jogo dos erros, etc. Cada jogo terá sua explicação inicial e sua resolução ao final da revista para consulta e verificação dos resultados dos jogos.

\section{Etapa III - Diagramação da Revista}

ReLAInEP - Revista Latino-America de Inovação e Engenharia de Produção, Curitiba, PR, Brasil, v. 3, n. 4, p. 25 - 50, 2015. 


\section{ReLAInEP}

Os jogos serão criados nos programas Word e Excel, sendo a formatação final da revista executada no programa Coreldraw, para divisão das páginas na sua referida ordem frente e verso. Os jogos serão organizados de forma a ocupar meia página de tamanho A4, ou seja, será impresso no formato 145 x $105 \mathrm{~cm}$, em papel couche. Uma opção de menor custo seria a impressão em papel sulfith e outra mais sustentável seria o uso de papel reciclado.

A composição final da revista constará numa organização dos jogos, respostas e referências em 04 folhas A4, contendo quatro páginas cada, incluindo as capas (frente e trás).

Um arquivo de impressão será criado no formato PDF, de forma a facilitar o uso posterior do arquivo sem perder a formatação.

\section{Etapa IV - Impressão da Revista}

O processo de impressão da revista será, no caso do protótipo, terceirizada com o apoio de uma gráfica rápida referência na região. Esse processo é fácil e de execução rápida, mas possui altos custos associados, caso não seja feito em grande escala.

Entretanto, para tornar o projeto mais completo, o produto e o processo poderiam ser projetados paralelamente, ou seja, poderia ser realizado um estudo de viabilidade de montagem de uma gráfica rápida para produzir o produto estudado.

Os dois planos citados para a impressão da revista poderão ser comparados no item de Planejamento dos Recursos.

\section{Etapa V - Dobra, Montagem e Corte dos excessos das páginas}

A etapa de acabamento da revista será executado segundo o tipo de impressão escolhido; caso seja terceirizado a própria empresa contratada o fará, caso seja na nova empresa a ser montada os processos devem ser previsto detalhadamente

\section{Etapa VI - Distribuição}

Após a finalização do produto, o mesmo será distribuído conforme a demanda prevista. No caso do projeto em estudo, o mesmo será apresentado em sala de aula para avaliação da disciplina e dos clientes potenciais.

\section{C - ESTRUTURA DO PRODUTO - LISTA DE MATERIAIS (BOM FINAL) \\ - Material de pesquisa (livros e internet) \\ - Computador com conexão à internet \\ - Softwares específicos (Word, Excel, Coreldraw) \\ - Equipamento para Impressão}

ReLAInEP - Revista Latino-America de Inovação e Engenharia de Produção, Curitiba, PR, Brasil, v. 3, n. 4, p. 25 - 50, 2015. 


\section{ReLAInEP}

- Toners de impressão preto e colorido

- 03 Folhas de papel A4 (tipo a definir) para o miolo

- 01 Folha de papel A4 (couche 250) para as capas

- 02 Grampos

\section{DOCUMENTO 5 - PROTÓTIPO FUNCIONAL}

Foram criados os dois protótipos, o virtual na forma de um arquivo de impressão em PDF; e o real na forma do exemplar impresso.
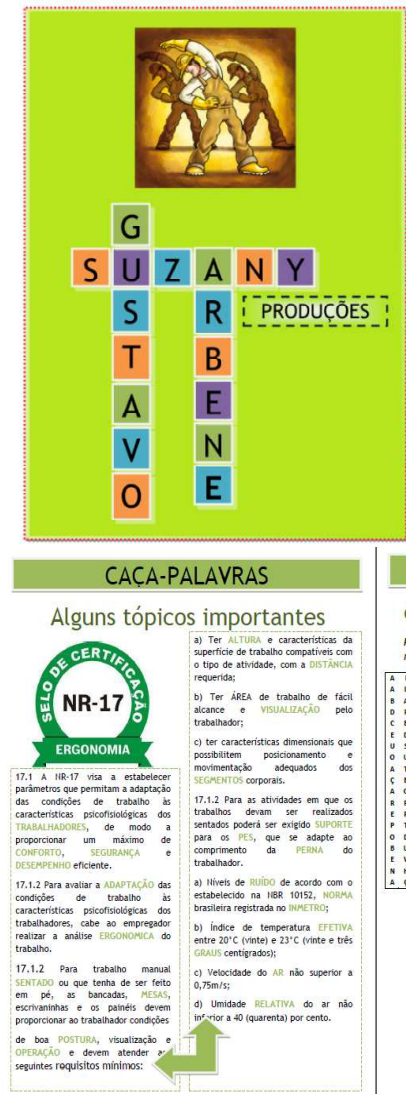
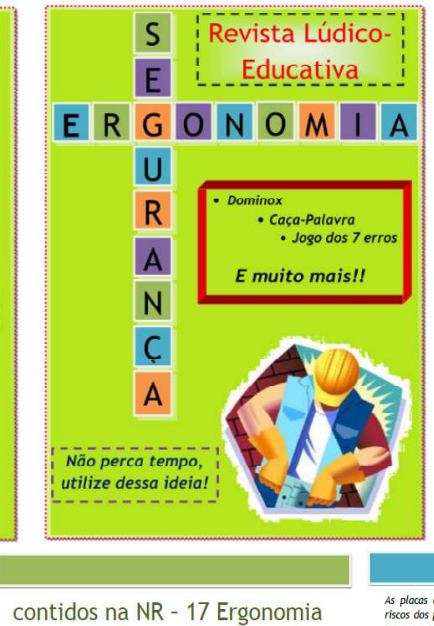

contidos na NR - 17 Ergonomia procure
no texto.
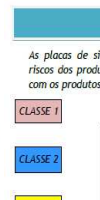

CLASSE

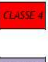

CuSSE 5

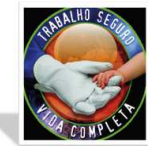

CASSE 6

"Segurança do Trabalho e ciência que, através de metodologia e técnicas apropriadas, estuda as possiveis causas de acidentes do trabalho, obje tivar
a prevença de suas ocorrencias." OSHA - Occupational Safety and Health Administration
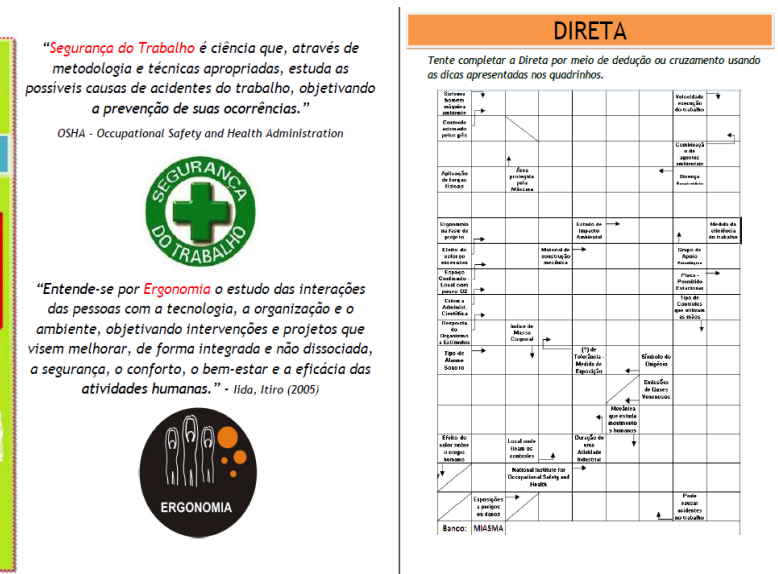

SINALIGACÃO

JOGO DOS ERROS

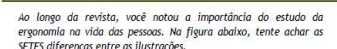

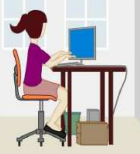

CLASSE 9
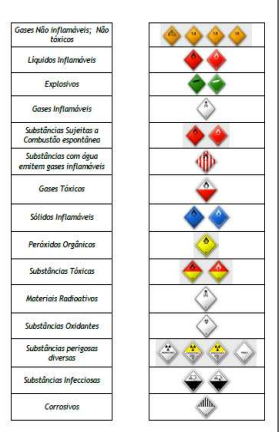

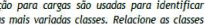

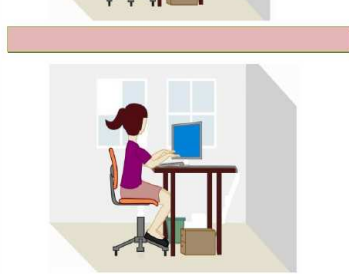

ReLAInEP - Revista Latino-America de Inovação e Engenharia de Produção, Curitiba, PR, Brasil, v. 3, n. 4, p. 25 - 50, 2015. 


\section{ReLAInEP}
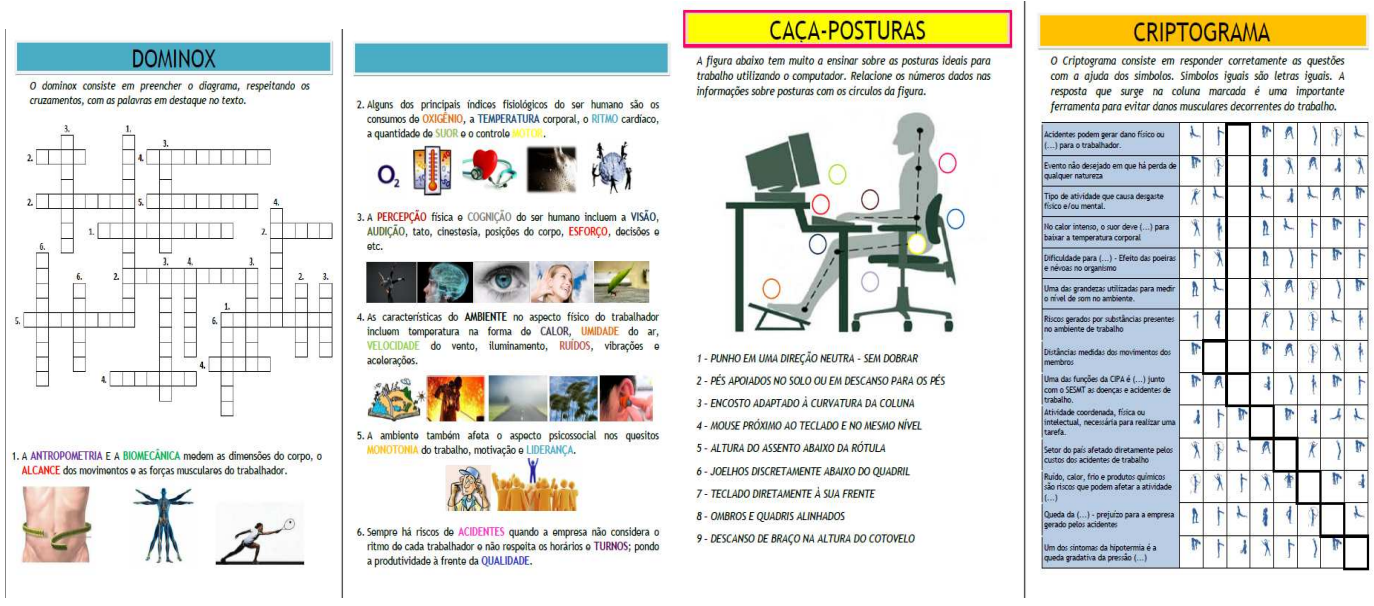

ReLAInEP - Revista Latino-America de Inovação e Engenharia de Produção, Curitiba, PR, Brasil, v. 3, n. 4, p. 25 - 50, 2015. 


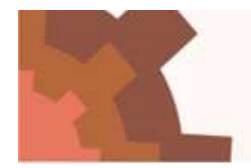

ReLAInEP
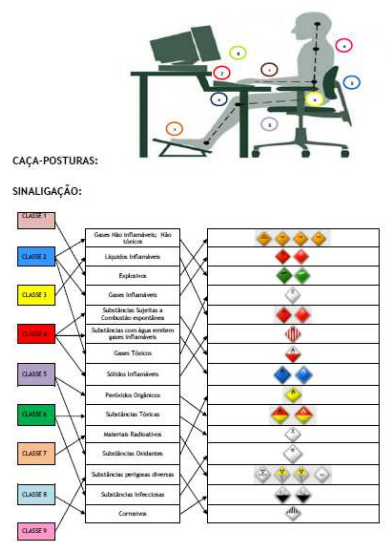
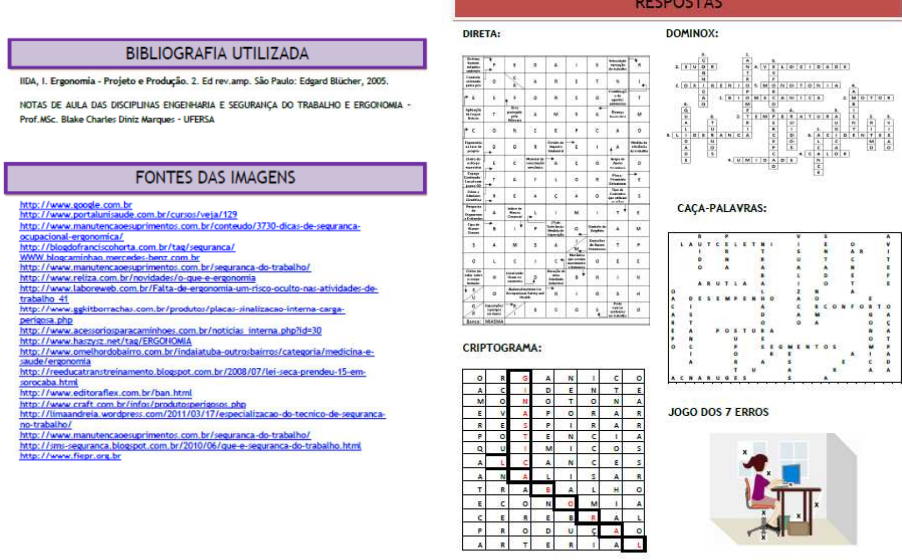

JoGo DOS 7 ERROS

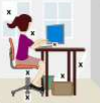

\section{DOCUMENTO 6 - PROJETO DOS RECURSOS}

\section{A - PLANO DO PROCESSO 1 - TERCEIRIZAÇÃO DA IMPRESSÃO}

O processo de terceirização da impressão é um processo simples e só envolve a escolha da empresa fornecedora do serviço. O custo é alto para pequenas tiragens, mas é reduzido com o aumento do número de exemplares.

No caso do protótipo realizado, já diagramado e formatado, o custo unitário para a impressão em papel couche foi o seguinte:

\section{1 unidade - R\$ 5,00 por folha $A 4-R \$ 20,00$ o custo total por unidade}

\section{0 unidades - $R \$ 3,00$ por folha $A 4-R \$ 12,00$ o custo total por unidade}

\section{0 unidades - R\$ 2,50 por folha A4 - R\$10,00 o custo total por unidade}

Contando que o valor que a maioria dos consumidores estaria disposta a pagar pela revista seria de $\mathrm{R} \$ 15,00$, haveria um lucro real de 50\% a partir de uma tiragem de 100 unidades, nessa condição de impressão terceirizada. Entretanto, o valor dos produtos comerciais similares (revistas de passatempos) vendidos em bancas e livrarias não ultrapassava o valor de $\mathrm{R} \$ 15,00$ e ainda contam com um número muito maior de jogos que o protótipo criado.

Outro fator a considerar é que o processo de criação não foi contemplado o nesta análise. Caso seja indicada pela demanda uma produção em larga escala, deverá ser

ReLAInEP - Revista Latino-America de Inovação e Engenharia de Produção, Curitiba, PR, Brasil, v. 3, n. 4, p. 25 - 50, 2015. 


\section{ReLAInEP}

programado um investimento em pessoal especializado para pesquisa, criação dos jogos e diagramação da revista, visando obter um conteúdo mais rico e extenso para cada exemplar.

Uma análise de mercado mais aprofundada poderia indicar uma previsão de demanda mais exata, o que justificaria o investimento em pessoal e o uso do processo de terceirização da impressão em tiragens maiores, já que o mesmo possui um alto custo associado.

\section{B - PLANO DO PROCESSO 2 - PROJETO DE UMA GRÁFICA RÁPIDA}

A segunda opção para iniciar a produção da REVISTA LÚDICO-EDUCATIVA seria a criação de uma empresa de artes gráficas, de pequeno porte, também conhecida como Gráfica Rápida.

O presente estudo é um levantamento simplificado do seguimento gráfico, sendo apresentados alguns aspectos iniciais a serem considerados para a montagem deste negócio, baseado em informações obtidas nos sites do SEBRAE (Serviço Brasileiro de Apoio às Micro e Pequenas Empresas) a da ABIGRAF (Associação Brasileira da Indústria Gráfica).

O setor gráfico representa $1 \%$ do PIB brasileiro e 3,3\% do PIB industrial, sendo responsável pela geração de mais de 200 mil postos de trabalho diretos. Nos últimos 15 anos investiu perto de US\$ 6 bilhões em máquinas, equipamentos e novas tecnologias (ABIGRAF, 2012).

A área mínima para uma pequena oficina gráfica funcionar é de aproximadamente, 60 $\mathrm{m}^{2}$. Pode ser um galpão ou barracão e até uma loja comercial, ou ainda uma sala. Divida o espaço em três ambientes: depósito, escritório e produção. $\mathrm{Na}$ área da produção, o lay-out mais indicado é dispor as máquinas seguindo a ordem do processo de impressão: cortadeira, máquina offset, balcão de blocagem alceamento e acabamento, picotadeira, guilhotina e grampeador. (SEBRAE, 2012).

Os equipamentos básicos fundamentais para o investimento inicial são apresentados a seguir (SEBRAE, 2012):

- Máquina duplicadora digital;

- Tambor preto (impressões monocromáticas);

- Tambores de coloridos;

ReLAInEP - Revista Latino-America de Inovação e Engenharia de Produção, Curitiba, PR, Brasil, v. 3, n. 4, p. 25 - 50, 2015. 


\section{ReLAInEP}

- Sistema de interface;

- Sistema de numeração;

- Guilhotina manual;

- Picotadeira;

- Alceador;

- Dobradeira;

- Refiladora;

- Guilhotina manual para acabamento;

- Perfurador para espirais;

- Acessórios para encadernação: capas de PVC, espirais, alicate, colocadora de espirais, etc.;

- Computador de última geração, com recursos de multimídia, modem, etc.;

- Impressora jato de tinta colorida;

- Impressora laser;

- Scanner de mesa;

- Linha telefônica com aparelho e fax;

- Ar refrigerado e

- Bebedouro.

Uma gráfica rápida deve contar com o seguinte quadro de pessoal de criação, operação e apoio:

- Atendente

- Profissional e informática

- Encarregado de produção e

- Auxiliar de produção

Conforme a estrutura do empreendimento, o valor estimado, para o empreendedor iniciar esse tipo de negócio, pode ficar em torno de: $\mathrm{R} \$ 75.000,00$.

-Capital de Giro: R \$ 40.000,00

-Investimento em equipamentos e instalações: $\mathrm{R} \$ 35.000,00$

-Faturamento bruto mensal previsto: R \$ 15.000,00

ReLAInEP - Revista Latino-America de Inovação e Engenharia de Produção, Curitiba, PR, Brasil, v. 3, n. 4, p. 25 - 50, 2015. 


\section{ReLAInEP}

O faturamento bruto mensal citado pelo estudo encontrado no site do SEBRAE inclui serviços comerciais e industriais em geral, mas para o caso da REVISTA LÚDICOEDUCATIVA seria necessária uma tiragem mínima de 1000 unidades, vendidas a R 15,00 para obter esse mesmo faturamento. Além disso, não haveria necessidade da revista ser o único produto da gráfica, podendo haver uma diversificação do portfólio de produtos, visando a maximização dos resultados financeiros.

Devem ser considerados mais os custos fixos e variáveis associados a esta produção para se prever o retorno sobre o investimento. Entretanto, caso se confirmasse uma demanda real para o produto poderia ser uma excelente opção para um potencial empreendedor.

\section{DOCUMENTO 7 - PLANO DE FIM DE VIDA}

$\mathrm{O}$ fim de vida do produto previsto se dará quando o consumidor encerrar o preenchimento da revista e despertar o desejo de adquirir outra. Assim, a empresa poderá participar deste processo de fim de vida nas seguintes formas:

- Como se trata de um produto fabricado de papel poderá ser reciclado e a empresa poderá oferecer um incentivo financeiro ao consumidor, na forma de desconto em um novo exemplar para cada retorno de uma revista já utilizada;

- A empresa poderá efetuar o recolhimento de exemplares danificados no transporte ou no ponto de venda, para dar-lhes um destino final adequado;

- Os exemplares que não forem vendidos num determinado período poderão ser recolhidos e novamente encadernados, juntamente com outros exemplares antigos, para ser revendido a preços promocionais;

- A empresa poderá contratar uma empresa especializada em reciclagem para recuperar as revistas usadas e produzir o papel reciclado;

- A empresa poderá lançar uma linha de revistas fabricadas à base de papel reciclado para reaproveitar o retorno deste papel à produção.

\section{CONCLUSÃO}

$\mathrm{O}$ presente projeto atingiu os objetivos propostos, na medida em que permitiu o aprendizado dos modelos mais utilizados para o Projeto e Desenvolvimento de Produtos; a

ReLAInEP - Revista Latino-America de Inovação e Engenharia de Produção, Curitiba, PR, Brasil, v. 3, n. 4, p. 25 - 50, 2015. 


\section{ReLAInEP}

aplicação dos mesmos a um projeto proposto; e a concretização do projeto, através da execução de um protótipo.

Essas experiências permitiram conhecer os caminhos dos projetos em uma organização, mesmo sendo executados dentro da universidade; permitindo ainda a experiência de criar um produto inovador, útil e divertido para ser usado como material didático.

O produto obteve grande aceitação pelos consumidores, indicando um alto potencial como empreendimento no setor gráfico, num mercado que se encontra aquecido e em franca expansão.

\section{REFERÊNCIAS}

DINSMORE, P. C., NETO, F. H. S., Gerenciamento de projetos: como gerenciar seu projeto com qualidade, dentro do prazo e custos previsíveis. 1 ed. Rio de Janeiro: Qualitymark, 2006.

DINSMORE, P. C., CAVALIERI, A. Como se tornar um profissional em Gerenciamento de Projetos. 4. ed. Rio de Janeiro: Qualitymark, 2007.

KEELLING, Ralph. Gestão de Projetos: uma abordagem global. Filosofia. São Paulo: Saraiva, 2002 p. 23-69.

ROZENFELD, H., FORCELLINI, F.A., AMARAL, D.C., TOLEDO, J.C., SILVA, SLACK, N., CHAMBERS, S., JOHNSTON, R. Administração da Produção. 2. Ed. São Paulo: Atlas, 2002.

S.L., ALLIPRANDINI, D.H., SCALICE, R.K. Gestão de Desenvolvimento de Produtos Uma referência para a melhoria do processo. São Paulo: Saraiva, 2006.

VALERIANO, Dalton L. Gerenciamento estratégico e administração por projetos. São Paulo: Makron Books, 2001.

Sites consultados:

http://www.sebrae-sc.com.br/ideais/default.asp?vcdtexto=3847\&\%5E $\% 5 \mathrm{E}$

http://www.abigraf.org.br/

http://portaldasartesgraficas.com/ficheiros/fases_projeto_grafico.pdf

http://como-abrir-o-seu-negocio.blogspot.com.br/2011/04/como-abrir-montar-uma

grafica.html

http://www.empregabrasil.org.br/arqs/envcw79aklysd.htm

ReLAInEP - Revista Latino-America de Inovação e Engenharia de Produção, Curitiba, PR, Brasil, v. 3, n. 4, p. 25 - 50, 2015. 